\title{
A Comparison of Fixed Cost Based Transmission Pricing Methods
}

\author{
M. Murali ${ }^{*}$, M. S. Kumari, M. Sydulu \\ Electrical Engineering Department, National Institute of Technology, Warangal, 506004, India
}

\begin{abstract}
In the restructured power market, it is necessary to develop an appropriate pricing scheme that can provide the useful economic information to market participants, such as generation, transmission companies and customers. Proper pricing method is needed for transmission network to ensure reliability and secure operation of power system. Accurately estimating and allocating the transmission cost in the transmission pricing scheme still remains challenging task. This paper gives an overview of different costs incurred in transmission transaction, types of transmission transactions and the transmission pricing methodologies. Embedded as well as Incremental cost methods are explained. It mainly focussed on determining the embedded transmission cost by various methods and compared the results for 6bus, IEEE 14bus and RTS 24 bus systems.
\end{abstract}

Keywords Bialek Tracing, Embedded Cost, GGDF, MVA-Mile, MW-Mile, Postage Stamp, Tracing

\section{Introduction}

The rapidly changing business environment for electric power utilities all around the world has resulted in unbundling of services provided by these utilities. With the introduction of restructuring into the electric power industry, the price of electricity has become the focus of all activities in the power market. The objective of transmission pricing is to recover all or part of the existing and new cost of transmission system. Pricing of transmission services plays a crucial role in determining whether providing transmission crucial role in determining whether providing transmission services is economically beneficial to both the wheeling utility and the wheeling customers. Engineering analysis which deals mainly with determining the feasibility and the cost of providing transmission services is only one of many considerations in the overall process of pricing transmission services. So, it is important to distinguish between transmission costs and prices.

\subsection{Categories of Transmission Transactions}

The following are the categories[2,3] of transmission transactions:

\subsubsection{Firm Transmission Transactions}

These transactions are not subject to discretionary interruptions and are specified in terms of $\mathrm{MW}$ of transmission

* Corresponding author:

matcha.murali@gmail.com (M.Murali)

Published online at http://journal.sapub.org/eee

Copyright (C) 2011 Scientific \& Academic Publishing. All Rights Reserved capacity that must be reserved for the transaction. The transco makes arrangements for enough capacity on the network to meet these transaction needs. These could either be on a long-term basis, in the order of years or on short-term contracts (up to one year).

\subsubsection{Non-firm Transmission Transactions}

These transactions may be curtailable or as-available. Curtailable transactions are ongoing transactions that may be curtailed at the utility's discretion. As-available transactions are short-term, mainly economy, transactions that take place when transmission capacity becomes available at specific areas of the system at specific times.

\subsubsection{Long-term Transmission Transactions}

A long-term transaction takes place over a period spanning several years. Long-term transmission transaction is long enough to allow building new transmission facilities. Transmission service provided as part of long -term firm power sales is an example of long-term transaction[3].

\subsubsection{Short-term Transmission Transactions}

A short-term transmission transaction may be as short as a few hours to as long as a year or two and as such are not generally associated with transmission reinforcements. Short term transaction may be a bilateral contract or pool trading[3].

\subsection{Components of the Transmission Cost}

The major components of the transmission cost of transmission transactions are:[17] 


\subsubsection{Operating Cost}

This is the cost due to generation rescheduling and redispatches to minimize the system losses, relieve congested transmission lines and enhance the system voltage profile.

\subsubsection{Opportunity Cost}

Benefits of all the transactions that the utility forgoes due to operating constraints. It is defined as costs that may be encountered in the transmission constrained case where the wheeling may prevent the transmission capacity. In other words it is the profit obtained to ISO during congestion in the system.

\subsubsection{Reinforcement Cost}

Capital cost of new transmission facilities needed to accommodate the transaction. It also includes the installation of additional reactive power resources to support the transaction.

\subsubsection{Embedded Cost}

The allocated cost of existing transmission facilities used by the transmission transaction. It includes:

Investment costs (including returns and depreciation of capital equipment) which is the highest proportion of the overall cost.

Administrative and general costs including scheduling and coordination services, billing and accounting staff, and salaries.

Investment for operation and maintenance costs.

Cost of voltage control and reactive power support.

Operating cost, opportunity cost and reinforcement cost constitute the incremental cost of the transmission transaction. Incremental costs are two types. They are short run and long run incremental costs. "Short-Run Incremental Cost" refer to operating cost and opportunity cost, "Long-Run Incremental Cost" refers to operating cost, opportunity cost and reinforcement cost. "Congestion Cost" is also called opportunity cost and "Embedded Cost" is also called existing system cost.

\section{Transmission Pricing Methods}

The main objective of any transmission pricing method is to recover the transmission system cost plus some profit. Transmission pricing methods are the overall processes of translating transmission costs into overall transmission charges. These methods are shown in Figure 1:

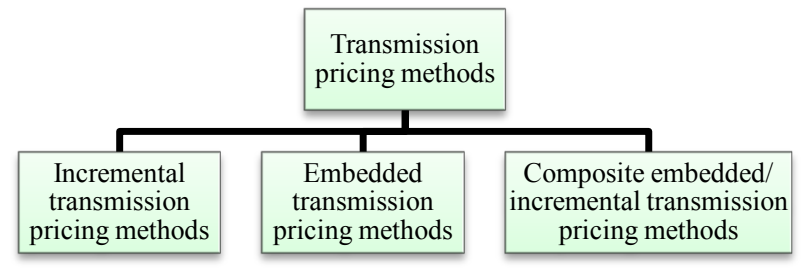

Figure 1. Different transmission pricing methods.

\subsection{Incremental Transmission Pricing}

These pricing methods allocate the incremental cost (i.e., variable cost) of the transmission transaction. Figure 2 shows different types of incremental pricing methods.

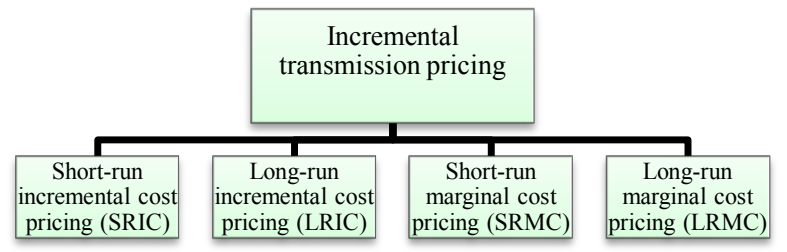

Figure 2. Types of incremental transmission pricing methods.

\subsubsection{Short-run Incremental Cost Pricing (SRIC)}

This pricing methodology entails evaluating and assigning the operating costs associated with a new transmission transaction to that transaction. The transmission transaction operating costs can be estimated using an optimal power flow (OPF) model that accounts for all operating constraints including transmission system (static or dynamic security) constraints and generation scheduling constraints.

\subsubsection{Long-run Incremental Cost Pricing (LRIC)}

This pricing methodology entails evaluating all long-run costs (operating and reinforcement costs) necessary to accommodate a transmission transaction and assigning such costs to that transaction. The reinforcement cost component of a transmission transaction can be evaluated based on the changes caused in long-tem transmission plans due to the transmission transaction.

\subsubsection{Short- run Marginal Cost Pricing (SRMC)}

The short-run marginal cost of a Transco is the cost of supplying an additional $1 \mathrm{MW}$ of power in a transaction. SRMC is the difference in marginal costs of supply bus and delivery bus. The marginal costs of two buses can be determined from the optimal power flow solution as the dual variables associated with the demand balance equation. The transaction price can be determined by multiplying the power transaction with the SRMC to obtain SRMC based price.[4,5,6,7] SRMC takes into consideration the variable costs incurred by the transaction i.e., the operating cost but not the reinforcement cost.

$$
\mathrm{SRMC}_{\mathrm{t}}=\sum_{i \in B_{t}} B M C_{i} * P_{i, t}
$$

where, $\mathrm{BMC}_{\mathrm{i}}$ is the bus i marginal cost, $\mathrm{P}_{\mathrm{i}, \mathrm{t}}$ is the injected power at bus $i$ due to transaction $t$ and $B_{t}$ is the set of transmission buses involved in the transaction $t$. The bus marginal cost of power can be calculated using OPF sensitivity methods[12].

SRMC over the life of the transaction could be estimated using a detailed chronological production simulation model that incorporates all transmission constraints. SRMC prices for a transmission transaction can be negative.

Merits

Gives correct price signals to generators and loads for ef- 
ficient location and operation.

Demerits

Recovers operating costs only.

Provides distorted cost messages in the presence of constraints.

Deters transmission investment.

Volatility of the price.

\subsubsection{Long-run Marginal Cost Pricing (LRMC)}

LRMC determines the present value of future investments required to support a marginal increase in demand at different locations in the system, based on peak scenarios of future demands and supply growth[8]. In this pricing methodology the marginal operating and reinforcement costs of the power system are used to determine the prices for a transmission transaction.

\subsection{Embedded Transmission Pricing}

These pricing methods allocate the embedded system costs i.e., fixed cost among transmission system users. Embedded pricing methods can be categorized as in Figure 3:

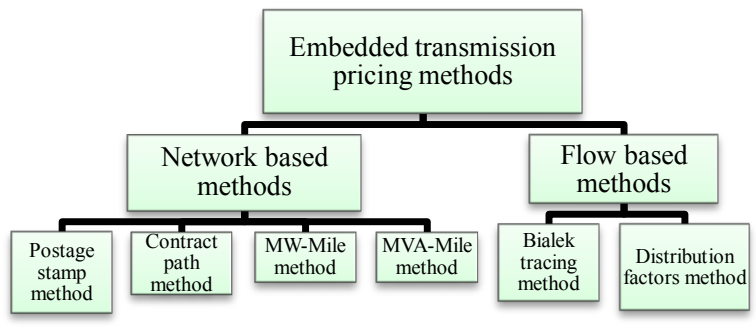

Figure 3. Types of embedded transmission pricing methods.

\subsubsection{Network Based Methods}

These methods depend on the structure of the transmission system but do not recognize the physical laws governing its operation[8].

a) Postage Stamp Method

Postage-stamp rate method is traditionally used by electric utilities to allocate the fixed transmission cost among the users of firm transmission service. This method is an embedded cost method, which is also called the rolled-in embedded method. This method does not require power flow calculations and is independent of the transmission distance and network configuration. The magnitude of the transacted power for a particular transmission transaction is usually measured at the time of system peak load condition:

$$
\mathrm{R}_{\mathrm{T}=\mathrm{TC}} *\left(\mathrm{P}_{\mathrm{t}} / \mathrm{P}_{\text {peak }}\right)
$$

Where $R_{t}$ is the transmission price for transaction $t$, TC is the total transmission charges and $\mathrm{P}_{\mathrm{t}}$ and $\mathrm{P}_{\text {peak }}$ are transaction $t$ load and the entire system load at the time of system peak load condition[13]. The main purpose of using this methodology is the entire system is considered as a centrally operated integrated system. This method is simpler. Since this method ignores the actual system operation, it is likely to send incorrect economic signal to transmission customers.

b) Contract Path Method

In this method a specific path between the points of de- livery and receipt is selected for a wheeling transaction. This path is called the "contract path" and is selected by the utility company and the wheeling customer usually without performing a power flow study to identify the transmission facilities that are actually involved in the transaction[13]. This method also ignores the actual system operation.

c) Distance Based MW-Mile Method

This method allocates the transmission charges based on the magnitude of transacted power and the geographical distance between the delivery point and the receipt point i.e., it is the product of power due to a transaction times the distance this power travels in the network[8]. This method is DC power flow based method.

$$
T C_{t}=T C \times \frac{\sum_{k \in K} C_{k} L_{k} M W_{t, k}}{\sum_{t \in T} \sum_{k \in K} C_{k} L_{k} M W_{t, k}}
$$

$\operatorname{In}(3)$

$$
\begin{array}{ll}
\mathrm{TC}_{\mathrm{t}} & =\text { cost allocated to transaction } \mathrm{t} \\
\mathrm{TC} & =\text { total cost of all lines in } \$ \\
\mathrm{Lk} & =\text { length of line } \mathrm{k} \text { in mile } \\
\mathrm{Ck} & =\text { cost per MW per unit length of line } \mathrm{k} \\
\mathrm{MW}_{\mathrm{t}, \mathrm{k}} & =\text { flow in line } \mathrm{k} \text {, due to transaction } \mathrm{t} \\
\mathrm{T} & =\text { set of transactions } \\
\mathrm{K} & =\text { set of lines }
\end{array}
$$

d) MVA-Mile Method

The MVA-Mile method is an extended version of the MW-Mile method. It takes into consideration both real power and reactive power where as MW-Mile method considers only real power. This method also allocates the transmission charges based on the magnitude of power and the geographical distance between the delivery point and the receipt point. This method is AC power flow based method.

\subsubsection{Flow Based Methods}

This approach allocates the charges of each transmission facility to a wheeling transaction based on the extent of use of that facility by the transaction. This is determined as a function of magnitude, the path, and the distance travelled by the transacted power. The flow based methods are Bialek tracing method and Distribution factors method.

a) Bialek Tracing Method

This algorithm works only on lossless flows when the flows at the beginning and end of each line are the same. The simplest way of obtaining lossless flows from the lossy ones is by assuming that a line flow is an average over the sending and receiving end flows and by adding half of the line loss to the power injections at each terminal node of the line[14].

The total flow $\mathrm{P}_{\mathrm{i}}$ through node i (i.e., the sum of inflows or outflows) may be expressed, when looking at the inflows as[15]

$\operatorname{In}(4)$

$$
P_{i j}^{g}=\frac{P_{i j}^{g}}{P_{i}^{g}} \sum_{k=1}^{n}\left[A_{u}^{-1}\right]_{i k} P_{G k} ; j \in \alpha_{i}^{d}
$$




$$
\begin{array}{ll}
=-\frac{\left|P_{j i}\right|}{P_{j}} & \mathrm{j} \in \alpha_{i}^{u} \\
=0 & \text { otherwise }
\end{array}
$$

and

$P_{i j}^{g}=$ an unknown gross line flow in line $\mathrm{i}-\mathrm{j}$

$P_{i}^{g}=$ an unknown gross nodal power flow through node $\mathrm{i}$

$A_{u}=$ upstream distribution matrix

$\mathrm{P}_{\mathrm{Gk}}=$ generation in node $\mathrm{k}$

$\alpha_{i}^{d}=$ set of nodes supplied directly from node $\mathrm{i}$

$\alpha_{i}^{u}=$ set of buses supplying directly to bus $\mathrm{i}$

b) Distribution Factors Method

Distribution factors are calculated based on DC load flows. These factors are used to determine the impact of generation and load on transmission flows. The various distribution factors are Generation shift distribution factors (GSDF's) and Generalized Generation/ load distribution factors (GGDF's/GLDF's) have been used extensively in power system security analysis to approximate the transmission line flows and generation /load values. GSDF's or A factors provide line flow changes due to a change in generation. These factors can be used in determining maximum transaction flows for bounded generation and load injections. GGDF's are applied to estimate the contribution by each generator $[15,16]$ to the line flow on the transmission grid and GLDF's determine the contribution of each load to line flows.

\section{Results}

Tables 1 to 8 present the cost of one MW generation for each generator using various pricing methods applied to 6 bus system, IEEE-14 bus system and RTS 24 bus systems. 6 bus system[19] has generators at bus numbers 1, 2, 3. In this paper line lengths are assumed to be proportional to the line reactance. For transformers line lengths are neglected and are taken as zero. Postage stamp method doesn't consider system line lengths, and hence gives a very inferior result compared to other methods. MW-Mile method uses DC power flow solution and accounts for line lengths. MVA-Mile method uses AC power flow and also accounts for the line lengths. GGDF method uses DC power flow and Power transfer Distribution factors for pricing and traces the actual power flow of each line by each participant. Bialek tracing method uses AC power flow algorithm and it also traces the actual power flow of each line by each participant. The results shows that, power flow tracing based methods present more accurate pricing compared to postage stamp method, MW-Mile method and MVA-Mile method. Tables 1, 2, 3, 4 illustrates cost per MW generation for each generator using various methods for 6 bus system Tables 5, 6, 7 illustrates cost per MW generation for each generator using various methods for IEEE-14 bus system[18] which has Generators at bus numbers 1, 2.Flow based Bialek tracing method is the best way of transmission pricing, which considers AC power flow and total line flows. Table 8 demonstrates the results obtained for RTS 24 bus system[20] containing 10 generators. In all the methods for all bus systems transmission charges are allocated to generators only.

\begin{tabular}{|c|c|c|c|c|}
\hline \multirow{3}{*}{ Line $\mathrm{k}$} & \multirow{3}{*}{$\begin{array}{c}\text { Line cost } \\
C_{k}(\$)\end{array}$} & \multicolumn{3}{|c|}{ Postage stamp method } \\
\hline & & G1 & G2 & G3 \\
\hline & & $\mathrm{C}_{\mathrm{k}} \mathrm{MW}_{1, \mathrm{k}}$ & $\mathrm{C}_{\mathrm{k}} \mathrm{MW}_{2, \mathrm{k}}$ & $\mathrm{C}_{\mathrm{k}} \mathrm{MW}_{3, \mathrm{k}}$ \\
\hline 1 & 10 & 97.05 & 97.05 & 97.05 \\
\hline 2 & 10 & 145.647 & 145.647 & 145.647 \\
\hline 3 & 10 & 118.766 & 118.766 & 118.766 \\
\hline 4 & 10 & 9.9452 & 9.9452 & 9.9452 \\
\hline 5 & 10 & 110.92 & 110.92 & 110.92 \\
\hline 6 & 10 & 51.64 & 51.64 & 51.64 \\
\hline 7 & 10 & 88.094 & 88.094 & 88.094 \\
\hline 8 & 10 & 64.42 & 64.42 & 64.42 \\
\hline 9 & 10 & 145.39 & 145.39 & 145.39 \\
\hline 10 & 10 & 14.028 & 14.028 & 14.028 \\
\hline 11 & 10 & 5.699 & 5.699 & 5.699 \\
\hline Total & 110 & 851.5992 & 851.5992 & 851.5992 \\
\hline \multicolumn{2}{|c|}{ Loss cost $(\$)$} & \multicolumn{3}{|c|}{84.46295} \\
\hline \multicolumn{2}{|c|}{ Total cost of each generator $(\$)$} & 879.75 & 879.75 & 879.75 \\
\hline \multicolumn{2}{|c|}{ Total cost $(\$)$} & \multicolumn{3}{|c|}{2639.26} \\
\hline \multicolumn{2}{|c|}{ Each transaction cost $(\$)$} & 36.666 & 36.666 & 36.666 \\
\hline \multicolumn{2}{|c|}{ Cost (\$/MW) } & 0.3381 & 0.7333 & 0.6111 \\
\hline
\end{tabular}

Table 1. Postage Stamp Method Results for 6 Bus System

\begin{tabular}{|c|c|c|c|c|}
\hline \multirow{3}{*}{ Line $\mathrm{k}$} & \multirow{3}{*}{$\begin{array}{l}\text { Line cost } \\
\mathrm{C}_{\mathrm{k}} \mathrm{L}_{\mathrm{k}}(\$)\end{array}$} & \multicolumn{3}{|c|}{ MW-Mile method } \\
\hline & & G1 & G2 & G3 \\
\hline & & $\mathrm{C}_{\mathrm{k}} \mathrm{L}_{\mathrm{k}} \mathrm{MW}_{1, \mathrm{k}}$ & $\mathrm{C}_{\mathrm{k}} \mathrm{L}_{\mathrm{k}} \mathrm{MW}_{2, \mathrm{k}}$ & $\mathrm{C}_{\mathrm{k}} \mathrm{L}_{\mathrm{k}} \mathrm{MW}_{3, \mathrm{k}}$ \\
\hline 1 & 5780 & 48799.306 & 48799.306 & 48799.306 \\
\hline 2 & 2890 & 40043.035 & 40043.035 & 40043.035 \\
\hline 3 & 4630 & 51091.240 & 51091.240 & 51091.240 \\
\hline 4 & 2890 & 1785.7399 & 1785.7399 & 1785.7399 \\
\hline 5 & 2890 & 31286.763 & 31286.763 & 31286.763 \\
\hline 6 & 5780 & 31248.418 & 31248.418 & 31248.418 \\
\hline 7 & 4050 & 33450.487 & 33450.487 & 33450.487 \\
\hline 8 & 6940 & 39168.677 & 39168.677 & 39168.677 \\
\hline 9 & 1160 & 17369.841 & 17369.841 & 17369.841 \\
\hline 10 & 11560 & 15585.863 & 15585.863 & 15585.863 \\
\hline 11 & 5780 & 577.7244 & 577.7244 & 577.7244 \\
\hline Total & 54350 & 310407.1 & 310407.1 & 310407.1 \\
\hline \multicolumn{2}{|c|}{ Total cost $(\$)$} & \multicolumn{3}{|c|}{931221.297755} \\
\hline \multicolumn{2}{|c|}{ Each transaction cost $(\$)$} & 18116.666 & 18116.666 & 18116.666 \\
\hline \multicolumn{2}{|c|}{ Cost (\$/MW) } & 181.1667 & 362.3333 & 301.9444 \\
\hline
\end{tabular}

Table 2. MW-Mile Method Results for 6 Bus System 
Table 3. MVA-Mile Method Results for 6 Bus System.

\begin{tabular}{|c|c|c|c|c|}
\hline \multirow{3}{*}{ Line $\mathrm{k}$} & \multirow{3}{*}{ Line cost $\quad C_{k} L_{k}(\$)$} & \multicolumn{3}{|c|}{ MVA-Mile method } \\
\hline & & G1 & $\mathrm{G} 2$ & G3 \\
\hline & & $\mathrm{C}_{\mathrm{k}} \mathrm{L}_{\mathrm{k}} \mathrm{MW}_{1, \mathrm{k}}$ & $\mathrm{C}_{\mathrm{k}} \mathrm{L}_{\mathrm{k}} \mathrm{MW}_{2, \mathrm{k}}$ & $\mathrm{C}_{\mathrm{k}} \mathrm{L}_{\mathrm{k}} \mathrm{MW}_{3, \mathrm{k}}$ \\
\hline 1 & 5780 & 62662.8052 & 62662.8052 & 62662.8052 \\
\hline 2 & 2890 & 47445.2794 & 47445.2794 & 47445.2794 \\
\hline 3 & 4630 & 59595.4346 & 59595.4346 & 59595.4346 \\
\hline 4 & 2890 & 10631.3720 & 10631.3720 & 10631.3720 \\
\hline 5 & 2890 & 57534.290 & 57534.290 & 57534.290 \\
\hline 6 & 5780 & 46444.7241 & 46444.7241 & 46444.7241 \\
\hline 7 & 4050 & 41204.1692 & 41204.1692 & 41204.1692 \\
\hline 8 & 6940 & 76575.1978 & 76575.1978 & 76575.1978 \\
\hline 9 & 1160 & 30106.1825 & 30106.1825 & 30106.1825 \\
\hline 10 & 11560 & 18560.1565 & 18560.1565 & 18560.1565 \\
\hline 11 & 5780 & 17827.2732 & 17827.2732 & 17827.2732 \\
\hline Total & 54350 & 468586.885 & 468586.885 & 468586.885 \\
\hline \multicolumn{2}{|c|}{ Total cost $(\$)$} & \multicolumn{3}{|c|}{1405760.655195} \\
\hline \multicolumn{2}{|c|}{ Each transaction cost $(\$)$} & 18116.666 & 18116.666 & 18116.666 \\
\hline \multicolumn{2}{|c|}{ Cost (\$/MW) } & 167.0674 & 362.3333 & 301.9444 \\
\hline
\end{tabular}

Table 4. GGDF Method and Bialek Tracing Method Results for 6 Bus System.

\begin{tabular}{|c|c|c|c|c|c|c|c|}
\hline \multirow{3}{*}{$\begin{array}{c}\text { Line } \\
\mathrm{k}\end{array}$} & \multirow{3}{*}{ Line cost $C_{k} L_{k}(\$)$} & \multicolumn{3}{|c|}{ GGDF method } & \multicolumn{3}{|c|}{ Bialek Tracing method } \\
\hline & & G1 & $\mathrm{G} 2$ & G3 & G1 & $\mathrm{G} 2$ & G3 \\
\hline & & $\mathrm{C}_{\mathrm{k}} \mathrm{L}_{\mathrm{k}} \mathrm{MW}_{1, \mathrm{k}}$ & $\mathrm{C}_{\mathrm{k}} \mathrm{L}_{\mathrm{k}} \mathrm{MW}_{2, \mathrm{k}}$ & $\mathrm{C}_{\mathrm{k}} \mathrm{L}_{\mathrm{k}} \mathrm{MW}_{3, \mathrm{k}}$ & $\mathrm{C}_{\mathrm{k}} \mathrm{L}_{\mathrm{k}} \mathrm{MW}_{1, \mathrm{k}}$ & $\mathrm{C}_{\mathrm{k}} \mathrm{L}_{\mathrm{k}} \mathrm{MW}_{2, \mathrm{k}}$ & $\mathrm{C}_{\mathrm{k}} \mathrm{L}_{\mathrm{k}} \mathrm{MW}_{3, \mathrm{k}}$ \\
\hline 1 & 5780 & 200960.504 & 35530.054 & 19032.529 & 168052.644 & 0.0 & 0.0 \\
\hline 2 & 2890 & 103219.682 & 6108.325 & 10801.098 & 126504.836 & 0.0 & 0.0 \\
\hline 3 & 4630 & 136657.198 & 18674.924 & 2058.401 & 164786.76 & 0.0 & 0.0 \\
\hline 4 & 2890 & 27007.031 & 21371.361 & 43021.173 & 3244.213 & 5579.07 & 0.0 \\
\hline 5 & 2890 & 5478.859 & 47746.705 & 40634.726 & 35534.37 & 61108.42 & 0.0 \\
\hline 6 & 5780 & 36626.461 & 47000.107 & 10118.685 & 33306.7059 & 57277.515 & 0.0 \\
\hline 7 & 4050 & 69622.344 & 47810.813 & 17081.696 & 40071.716 & 68911.298 & 0.0 \\
\hline 8 & 6940 & 11617.052 & 15767.633 & 113355.452 & 2359.01832 & 4056.8019 & 126087.205 \\
\hline 9 & 1160 & 12781.947 & 5942.611 & 33384.964 & 907.872 & 1561.268 & 48524.9051 \\
\hline 10 & 11560 & 49460.832 & 22753.456 & 25456.698 & 36607.791 & 13805.576 & 0.0 \\
\hline 11 & 5780 & 29615.045 & 1510.971 & 26370.900 & 6068.986 & 1581.2868 & 2457.914 \\
\hline Total & 54350 & 683046.962 & 270216.965 & 341316.327 & 617444.916 & 213881.248 & 177070.024 \\
\hline \multicolumn{2}{|r|}{ Total cost $(\$)$} & \multicolumn{3}{|c|}{1294580.25535} & \multicolumn{3}{|c|}{1008396.1893} \\
\hline \multicolumn{2}{|c|}{ Each transaction cost $(\$)$} & 28676.169 & 11344.443 & 14329.387 & 33278.716 & 11527.65745 & 9543.6257 \\
\hline \multicolumn{2}{|r|}{ Cost (\$/MW) } & 286.761 & 226.888 & 238.823 & 306.888 & 230.5531 & 159.06 \\
\hline
\end{tabular}


Table 5. Postage Stamp Method Results for IEEE-14 Bus System.

\begin{tabular}{|c|c|c|c|}
\hline \multirow{2}{*}{ Line $\mathrm{k}$} & \multirow{2}{*}{ Line cost $\quad C_{k}(\$)$} & \multicolumn{2}{|c|}{ Postage stamp method } \\
\hline & & $\mathrm{C}_{\mathrm{k}} \mathrm{MW}_{1, \mathrm{k}}$ & $\mathrm{C}_{\mathrm{k}} \mathrm{MW}_{2, \mathrm{k}}$ \\
\hline 1 & 10 & 784.4853 & 784.4853 \\
\hline 2 & 10 & 377.4858 & 377.4858 \\
\hline 3 & 10 & 366.3253 & 366.3253 \\
\hline 4 & 10 & 280.5858 & 280.5858 \\
\hline 5 & 10 & 207.5823 & 207.5823 \\
\hline 6 & 10 & 118.1756 & 118.1756 \\
\hline 7 & 10 & 308.2598 & 308.2598 \\
\hline 8 & 10 & 140.3549 & 140.3549 \\
\hline 9 & 10 & 80.3806 & 80.3806 \\
\hline 10 & 10 & 220.4746 & 220.4746 \\
\hline 11 & 10 & 36.7807 & 36.7807 \\
\hline 12 & 10 & 38.9408 & 38.9408 \\
\hline 13 & 10 & 88.7531 & 88.7531 \\
\hline 14 & 10 & 0 & 0 \\
\hline 15 & 10 & 140.3549 & 140.3549 \\
\hline 16 & 10 & 26.1255 & 26.1255 \\
\hline 17 & 10 & 47.11 & 47.11 \\
\hline 18 & 10 & 19.0019 & 19.0019 \\
\hline 19 & 10 & 8.0814 & 8.0814 \\
\hline 20 & 10 & 28.2408 & 28.2408 \\
\hline Total & 200 & 3317.499 & 3317.499 \\
\hline \multicolumn{2}{|c|}{ Loss cost $(\$)$} & \multicolumn{2}{|c|}{133.942211} \\
\hline \multicolumn{2}{|c|}{ Total cost of each generator $(\$)$} & 3384.47 & 3384.47 \\
\hline \multicolumn{2}{|c|}{ Total cost $(\$)$} & \multicolumn{2}{|c|}{6768.94016} \\
\hline \multicolumn{2}{|c|}{ Each transaction cost $(\$)$} & 100 & 100 \\
\hline \multicolumn{2}{|c|}{$\operatorname{Cost}(\$ / M W)$} & 0.43 & 2.5 \\
\hline
\end{tabular}

Table 6. MW-Mile and MVA-Mile Method Results for IEEE-14 Bus System.

\begin{tabular}{|c|c|c|c|c|c|}
\hline \multirow{2}{*}{ Line $\mathrm{k}$} & \multirow{2}{*}{ Line cost $\quad C_{k} L_{k}(\$)$} & \multicolumn{2}{|c|}{ MW-Mile method } & \multicolumn{2}{|c|}{ MVA-Mile method } \\
\hline & & $\mathrm{C}_{\mathrm{k}} \mathrm{L}_{\mathrm{k}} \mathrm{MW}_{1, \mathrm{k}}$ & $\mathrm{C}_{\mathrm{k}} \mathrm{L}_{\mathrm{k}} \mathrm{MW}_{2, \mathrm{k}}$ & $\mathrm{C}_{\mathrm{k}} \mathrm{L}_{\mathrm{k}} \mathrm{MW}_{1, \mathrm{k}}$ & $\mathrm{C}_{\mathrm{k}} \mathrm{L}_{\mathrm{k}} \mathrm{MW}_{2, \mathrm{k}}$ \\
\hline 1 & 59.17 & 4375.0468 & 4375.0468 & 4680.9 & 4680.9 \\
\hline 2 & 223.04 & 7931.2383 & 7931.2383 & 8431.0044 & 8431.0044 \\
\hline 3 & 197.97 & 6933.9228 & 6933.9228 & 7260.6853 & 7260.6853 \\
\hline 4 & 176.32 & 4868.756 & 4868.756 & 4948.772 & 4948.772 \\
\hline 5 & 173.88 & 3556.1915 & 3556.1915 & 3611.3018 & 3611.3018 \\
\hline 6 & 171.03 & 2065.1668 & 2065.1668 & 2014.3851 & 2014.3851 \\
\hline 7 & 42.11 & 1312.5645 & 1312.5645 & 1321.508 & 1321.508 \\
\hline 8 & 0 & 0 & 0 & 0 & 0 \\
\hline 9 & 0 & 0 & 0 & 0 & 0 \\
\hline 10 & 0 & 0 & 0 & 0 & 0 \\
\hline 11 & 198.9 & 627.0084 & 627.0084 & 815.321 & 815.321 \\
\hline 12 & 255.81 & 965.0617 & 965.0617 & 1046.638 & 1046.638 \\
\hline 13 & 130.27 & 1109.4895 & 1109.4895 & 1248.831 & 1248.831 \\
\hline 14 & 0 & 0 & 0 & 0 & 0 \\
\hline 15 & 0 & 0 & 0 & 0 & 0 \\
\hline 16 & 84.5 & 261.7488 & 261.7488 & 282.21 & 282.21 \\
\hline 17 & 270.38 & 1341.242 & 1341.242 & 1362.2593 & 1362.2593 \\
\hline 18 & 192.07 & 269.355 & 269.355 & 397.638 & 397.638 \\
\hline 19 & 199.88 & 144.4277 & 144.4277 & 178.554 & 178.554 \\
\hline 20 & 348.02 & 866.3673 & 866.3673 & 1030.715 & 1030.715 \\
\hline Total & 2723.35 & 36627.5879 & 36627.5879 & 38630.728925 & 38630.728925 \\
\hline \multicolumn{2}{|c|}{ Total cost $(\$)$} & \multicolumn{2}{|c|}{73255.175833} & \multicolumn{2}{|c|}{77261.457849} \\
\hline \multicolumn{2}{|c|}{ Each transaction cost $(\$)$} & 1361.675 & 1361.675 & 1361.675 & 1361.675 \\
\hline \multicolumn{2}{|c|}{ Cost $(\$ / M W)$} & 6.2177 & 34.0419 & 5.8593 & 34.0419 \\
\hline
\end{tabular}


Table 7. GGDF Method and Bialek Tracing Method Results for IEEE-14 Bus System.

\begin{tabular}{|c|c|c|c|c|c|}
\hline \multirow{2}{*}{ Line $\mathrm{k}$} & \multirow{2}{*}{ Line cost $C_{k} L_{k}(\$)$} & \multicolumn{2}{|c|}{ GGDF method } & \multicolumn{2}{|c|}{ Bialek Tracing method } \\
\hline & & $\mathrm{C}_{\mathrm{k}} \mathrm{L}_{\mathrm{k}} \mathrm{MW}_{1, \mathrm{k}}$ & $\mathrm{C}_{\mathrm{k}} \mathrm{L}_{\mathrm{k}} \mathrm{MW}_{2, \mathrm{k}}$ & $\mathrm{C}_{\mathrm{k}} \mathrm{L}_{\mathrm{k}} \mathrm{MW}_{1, \mathrm{k}}$ & $\mathrm{C}_{\mathrm{k}} \mathrm{L}_{\mathrm{k}} \mathrm{MW}_{2, \mathrm{k}}$ \\
\hline 1 & 59.17 & 9075.845 & 325.752 & 9306.547 & 0 \\
\hline 2 & 223.04 & 14634.561 & 1227.914 & 16788.656 & 0 \\
\hline 3 & 197.97 & 11543.006 & 2324.839 & 11817.217 & 3005.3024 \\
\hline 4 & 176.32 & 7892.390 & 1845.121 & 8033.773 & 2043.113 \\
\hline 5 & 173.88 & 5558.716 & 1553.666 & 5927.922 & 1507.563 \\
\hline 6 & 171.03 & 3334.272 & 796.061 & 3629.637 & 567.394 \\
\hline 7 & 42.11 & 2105.733 & 519.395 & 2440.359 & 193.466 \\
\hline 8 & 0 & 0 & 0 & 0 & 0 \\
\hline 9 & 0 & 0 & 0 & 0 & 0 \\
\hline 10 & 0 & 0 & 0 & 0 & 0 \\
\hline 11 & 198.9 & 1078.765 & 175.251 & 1564.289 & 124.013 \\
\hline 12 & 255.81 & 1635.514 & 294.609 & 1982.86 & 157.196 \\
\hline 13 & 130.27 & 1882.477 & 336.501 & 2292.032 & 181.707 \\
\hline 14 & 0 & 0 & 0 & 0 & 0 \\
\hline 15 & 0 & 0 & 0 & 0 & 0 \\
\hline 16 & 84.5 & 434.823 & 88.674 & 345.759 & 54.049 \\
\hline 17 & 270.38 & 2251.659 & 430.824 & 2137.757 & 334.18 \\
\hline 18 & 192.07 & 437.725 & 100.984 & 852.085 & 67.551 \\
\hline 19 & 199.88 & 246.963 & 41.892 & 359.889 & 28.531 \\
\hline 20 & 348.02 & 1486.422 & 246.312 & 2149.112 & 170.376 \\
\hline Total & 2723.35 & 63598.877 & 10307.8025 & 69627.899 & 8434.447 \\
\hline \multicolumn{2}{|c|}{ Total cost $(\$)$} & \multicolumn{2}{|c|}{73906.67975} & \multicolumn{2}{|c|}{78062.34683831} \\
\hline \multicolumn{2}{|c|}{ Each transaction cost $(\$)$} & 2343.522 & 379.827 & 2429.098 & 294.251 \\
\hline \multicolumn{2}{|c|}{ Cost $(\$ / \mathrm{MW})$} & 10.701 & 9.4957 & 10.4452 & 7.3563 \\
\hline
\end{tabular}

Table 8. Comparison of Various Methods for RTS 24 Bus System.

\begin{tabular}{|c|c|c|c|c|c|c|c|c|c|c|}
\hline & G1 & $\mathrm{G} 2$ & G3 & G4 & G5 & G6 & G7 & G8 & G9 & G10 \\
\hline \multicolumn{11}{|c|}{ Postage stamp method $\quad$ Total cost $=60082.95$} \\
\hline Each transaction cost $(\$)$ & 34 & 34 & 34 & 34 & 34 & 34 & 34 & 34 & 34 & 34 \\
\hline Cost $(\$ / M W)$ & -0.126 & 0.177 & 0.113 & 0.057 & 0.158 & 0.219 & 0.085 & 0.085 & 0.113 & 0.0515 \\
\hline \multicolumn{11}{|c|}{ MW-MILE method $\quad$ Total cost $=277997.312276$} \\
\hline Each transaction cost $(\$)$ & 212.34 & 212.34 & 212.34 & 212.34 & 212.34 & 212.34 & 212.34 & 212.34 & 212.34 & 212.34 \\
\hline Cost $(\$ / \mathrm{MW})$ & -0.585 & 1.1059 & 0.7078 & 0.3593 & 0.9876 & 1.3699 & 0.5309 & 0.5309 & 0.7078 & 0.3217 \\
\hline \multicolumn{11}{|c|}{ MVA-MILE method $\quad$ Total cost $=271847.739937$} \\
\hline Each transaction cost $(\$)$ & 212.34 & 212.34 & 212.34 & 212.34 & 212.34 & 212.34 & 212.34 & 212.34 & 212.34 & 212.34 \\
\hline Cost $(\$ / \mathrm{MW})$ & -0.792 & 1.1059 & 0.7078 & 0.3593 & 0.9876 & 1.3699 & 0.5309 & 0.5309 & 0.7078 & 0.3217 \\
\hline \multicolumn{11}{|c|}{ GGDF method Total cost $=862526.4524$} \\
\hline Each transaction cost $(\$)$ & 378.98 & 199.63 & 302.87 & 313.04 & 94.39 & 65.43 & 168.64 & 164.79 & 155.09 & 280.51 \\
\hline Cost $(\$ / M W)$ & -1.044 & 1.0398 & 1.0096 & 0.5297 & 0.439 & 0.4221 & 0.4216 & 0.412 & 0.517 & 0.425 \\
\hline \multicolumn{11}{|c|}{ Bialek tracing method $\quad$ Total cost $=262640.92634$} \\
\hline Each transaction cost $(\$)$ & 0 & 14.45 & 113.72 & 391.49 & 109.11 & 88.64 & 124.02 & 259.301 & 420.07 & 602.59 \\
\hline Cost $(\$ / M W)$ & 0 & 0.0753 & 0.3791 & 0.6624 & 0.5075 & 0.5719 & 0.3101 & 0.6483 & 1.4 & 0.913 \\
\hline
\end{tabular}




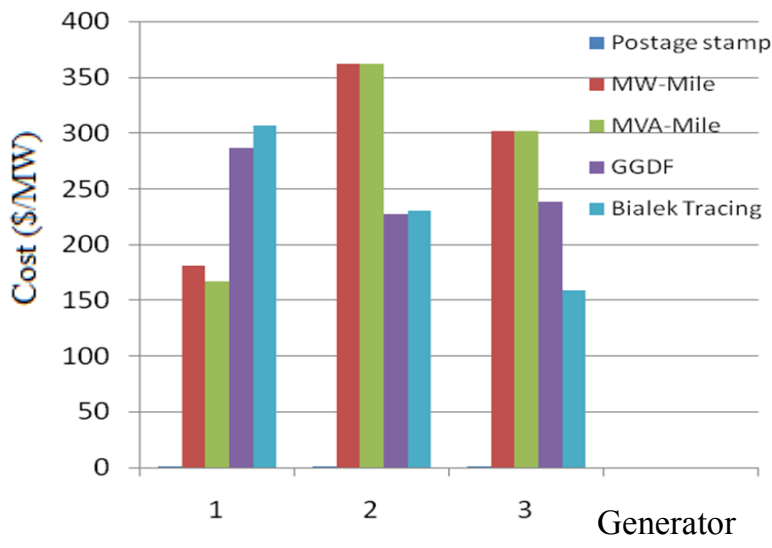

Figure 4. Comparison of 6 bus system results for different methods.

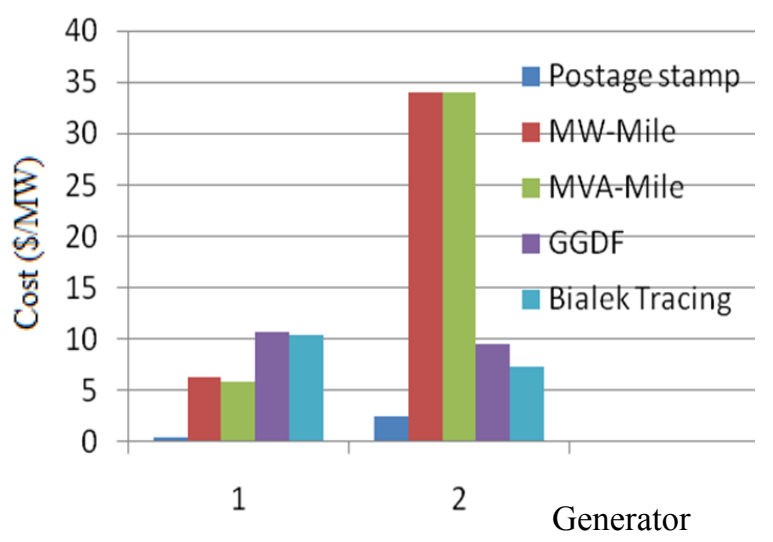

Figure 5. Comparison of 14 bus system results for different methods.

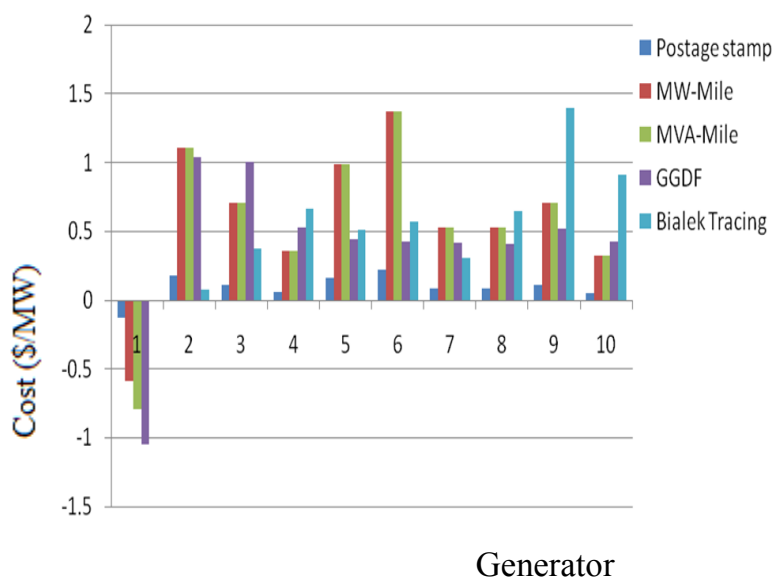

Figure 6. Comparison of 24 bus system results for different methods.

Figures 4, 5 and 6 show the cost per MW for 6 bus, 14 bus and 24 bus systems. Since postage stamp method values are near to zero, they are not visible in Figure 4. In Figure 6 at bus 1 i.e., at slack bus cost per MW is negative for all methods except for Bialek tracing method in which cost per MW is zero. Here slack bus generation is negative. Except Bialek remaining all methods calculates cost per MW for slack generator with negative generation as it is but only Bialek doesn't calculate any charges for slack generator because it has been treated by Bialek as a load bus. This is the one advantage in Bialek method.

\section{Conclusions}

In this paper embedded cost based methods of transmission pricing have been discussed. Different cost components incurred by the transmission transaction were explained. Case studies of postage stamp method, MW-Mile method, MVA-Mile method, Distribution factors method and Bialek tracing method for 6bus, IEEE14bus and RTS24 bus systems are presented. Postage stamp method for calculating embedded cost provides a very inferior solution compared to other network based and flow based methods. Bialek tracing method is the best way of transmission pricing, among all embedded cost based methods. It is observed that combination of incremental and embedded cost based methods could result in the recovery of true transmission system costs.

\section{ACKNOWLEDGEMENTS}

I wish to acknowledge my colleague Rakesh Chandra who helped me a lot in doing this work.

\section{REFERENCES}

[1] P.S. Kulkarni, O.P. Yadav, "SRMC based Transmission Pricing for Wheeling Transactions under Deregulated Environment of Power Sector”, IE (I) Journal-EL, May 2008.

[2] R.A.Wakefield, J.S.Graves and .F.Vojdani, "A transmission services costing framework", IEEE Transactions on Power systems, vol 12, No.2, May.1997.

[3] D.Shirmohammadi, C.Rajagoapalan, E.R.Alward and C.L.Thomas, "Cost of transmission transactions: An in-troduction", IEEE Transactions on Power systems, Nov.'91, pp.1546-1556.

[4] D.Shirmohammadi, P.R.Gribik, E.T.K.Law, J.H.Malinowski and R.E.O Donnel, "Evaluation of transmission network capacity use for wheeling transactions", IEEE transactions on Power Systems, Oct,'89, pp.1405-1413.

[5] Y.Z.Li and A.K.David, "Wheeling rates of reactive power flow under marginal cost pricing", IEEE Transactions on Power Systems, Aug.'94, pp.1263-1269

[6] C.W.Yu and A.K.David, "Pricing transmission services in the context of industry deregulation", IEEE Transactions on Power systems, Feb.'97, pp.503-510.

[7] M.C.Caramanis, R.E.Bohn and F.C.schweppe, "The cost of wheeling and optimal wheeling rates", IEEE Transac-tions on Power Systems, Feb.'86, pp.63-73.

[8] Mohamed A.M.Shaaban, "Cost-based pricing of trans-mission system services: An overview", IEEE Conference

[9] M.B. Rosenzweig, J. Bar-Lev, "Transmission Access and Pricing: Some Other Approaches", Public Utilities Fort-nightly, August 21, 1986, pp. 20-26.

[10] A.S. Holmes, "A Review and Evaluation of Selected 
Wheeling Arrangements and a Proposed General wheeling Tariff, FERC Paper, September 1983.

[11] D. Shirmohammdi, "An Engineering Perspective of Transmission Access and Wheeling", Proceedings of the 3rd International Symposium of Specialists in Electric Operational and Expansion Planning (SEPOPE III), Belo- Horizonte, Brazil, 1992.

[12] P.R. Gribik, D. Shirmohammadi, S. Hao, C.L. Thomas, "Optimal Power Flow Sensitivity Analysis", IEEE Transac-tion on Power Systems, Vol. 5, No. 3, August 1990, pp. 969-976.

[13] D. Shirmohammadi, Xisto Vieira, Boris Gorenstin, Mario V.P.Pereira, "Some fundamental technical concepts about cost based transmission pricing", IEEE Transac-tions on Power Systems, Vol. 11, No. 2,May 1996.

[14] J. Bialek, “Tracing the flow of electricity", IEE Proc-Gener. Transm. Distrb., Vol 143, No.4 July1996.

[15] Mohammad Shahidehpour, Hatim Yamin, Zuyi Li, "Market operations in Electric Power Systems", New York: Wiley, 2002.

[16] O.P.Rahi, Y.R.Sood, R.C.Chauhan, "Transmission pricing methodologies under restructured environment: An overview", NPSC 2004 paper.

[17] Kankar Bhattacharya, Math H.J.Bollen, Jaap E.Daalder, "Operation of Restructured Power Systems", Springer, 2001.

[18] P.K.Iyambo, R.Tzoneva, "Transient Stability Analysis of the IEEE 14-Bus Electric Power System", IEEE conference, Africon 2007.

[19] Ching-Tzong Su,Ji-Horng Liaw, "Power wheeling pricing using power tracing and MVA-KM method", IEEE Proto Power Tech Conference, Proto, Portugal,2001.

[20] P.F. Albrecht, M.P.Bhavaraju, B.E. Biggerstaff, R.Billinton, G.Elsoe Jorgensen, N.D.Reppen, P.B. Shortley, "IEEE Reliability Test System", IEEE Transaction on Power Apparatus and Systems, Vol. 1, PAS-98, No. 6, Nov. /Dec. 1979, pp.
2047-2054.

[21] Orfaros G.A, Tziasiou G.T, Georgilakis P.S, Hatziargyriou N.D, "Evaluation of transmission pricing methodologies for pool based electricity markets", IEEE conference, Power Tech, 2011.

[22] Manescu L.G, Rusinaru D, Dadulescu P, Anghelina V, "Usage based cost allocation for transmission cost un-der open access", IEEE conference, Power Tech, 2009.

[23] Majidi Q.M, Ghazizadeh M.S, Afsharnia S, “ A novel ap-proach to calculate transmission embedded cost based on MW-Mile method under deregulated environment", IEEE conference, Electric Power Conference, 2008.

[24] M.Yi, B.Jeyasurya, "Investigation of transmission cost allocation using a power flow tracing method", Pro-ceedings of IEEE Power Engineering Society General Meeting, June 2007, pp.1-7.

[25] N.Kumar, Y.R.V. Reddy, D.Das, N.P.Padhy, "Allocation of transmission charge by using MVA-Mile approaches for restructured Indian power utility", IEEE conference, Power and Energy Society General Meeting, 2011.

[26] Ghayeni M, Ghazi R, “Transmission network cost alloca-tion with nodal pricing approach based on Ramsey pricing concept", IET Journal on Generation, Transmis-sion \& Distribution, 2011, pp. 384-392.

[27] Yog Raj Sood, Narayana Prasad Padhy, H.O.Gupta, “A new method for allocating embedded cost of transmis-sion under deregulated environment of power system", IEEE conference, Power Engineering Society General Meeting, 2006.

[28] R.Bhakar, V.S.Sriram, N.P.Padhy, H.O.Gupta, "Probabilis-tic Game approaches for network cost allocation", IEEE Transactions on Power Systems, vol.25, No.1, February 2010.

[29] Alves C.C, Saavedra O.R, Vargas A, Arias M, Paucar V.L, "Transmission network cost allocation considering counterflows", IEEE Latin America Transactions, vol.9, No.3, June 2011, pp. 322-330 